\title{
ИНВЕНТАРИЗАЦИЯ ЗАЩИТНЫХ ЛЕСНЫХ НАСАЖДЕНИЙ НА ЗЕМЛЯХ СЕЛЬСКОХОЗЯЙСТВЕННОГО НАЗНАЧЕНИЯ
}

С. В. Богомазов, канд. с.-х. наук, доцент; О. С. Балакирева, студентка;

Е. В. Ефрремова, канд. с.-х. наук, доцент; О. А. Ткачук, канд. с.-х. наук, доцент;

А. В. Лянденбурская, ст. преподаватель; А. А. Левин, ассистент

Федеральное государственное бюджетное образовательное учреждение высшего образования «Пензенский государственный аграрный университет», Россия,

т. (8412) 628546, e-mail: s_bog@mail.ru

В статье приводится анализ хозяйственного использования лесных защитных насаждений на землях сельскохозяйственного назначения. Целью исследований являлась инвентаризация лесных защитных насаждений на территории Волчковского сельсовета Белинского района с целью сохранения и восстановления агролесомелиоративного фонда. В камеральных условиях создан актуальный картографический материал на базе космических снимков высокого и сверхвысокого разрешения, проведено визуальное дешифрирование с составлением векторного полигонального слоя текущего местоположения защитных лесных насаждений, определено количество дешифрированных объектов, их правовой статус и общая площадь (199,2 га). Расчет индекса NDVI показал, что состояние, не требующее проведения мероприятий по восстановлению (обновлению), имеют 77 лесных полос общей площадью 127,1 га; состояние, требующее мероприятий по восстановлению (обновлению), актуально для 31 лесной полосы площадью 70,4 га; полностью утраченная одна лесная полоса площадью 1,7 га. Разработана дорожная карта мероприятий по сохранению агролесомелиоративного фонда.

Ключевые слова: инвентаризация, защитные лесные насаждения, земли сельскохозяйственного назначения, географические информационные системы.

\section{Введение}

Лесные полосы, главная задача которых - защита полей от воздушной эрозии, сохранение влаги в почве, перестали выполнять свои функции. Созданные в 40-50е годы прошлого века лесные полосы пришли в запустение, разрослись, заполнив около семи процентов площадей пахотных земель. Сегодня лесополосы поджигают, вырубают, замусоривают. Собственники или арендаторы сельхозземель своевременно не организуют санитарные вырубки в лесополосах, считая это лишними и неоправданными затратами $[2,4,7]$.

Лесные насаждения активно препятствуют развитию и проявлению эрозии, задерживают осадки, предохраняют почву от разрушения каплями дождя и уменьшают поверхностный сток. Кроме того, лесные насаждения, снижая скорость ветра в приземном слое воздуха, предохраняют почву от разрушения ветром, выдувания и иссушения, способствуют равномерному отложению снега [3, 5, 8-11].

Половина всех защитных насаждений нуждается в срочном лесохозяйственном уходе и улучшении санитарного состояния. До $70 \%$ лесополос требуют капитальной реконструкции. Санитарные вырубки и уходные работы должны производиться собственниками (арендаторами) сельхозземель, однако, ответственности за невыполнение данных работ не предусматривается, поэтому «порядок» в лесополосах наводит, кто и как может, на свое усмотрение [6].

В некоторых субъектах на муниципальном уровне принят закон "О сохранении и защите лесонасаждений», который обязывает собственников и арендаторов земель сельскохозяйственного назначения, на которых расположены лесополосы, проводить уходные работы и санитарные вырубки. Один из пунктов закона предусматривает экономическое стимулирование сельхозтоваропроизводителей, осуществляющих агролесомелиоративные мероприятия для сохранения плодородия почвы [1].

Защитные лесонасаждения представляют собой сложные природные экосистемы, измененные в процессе сельскохозяйственного производства. При замене сложного естественного растительного покрова однообразным по видовому составу посевом и отсутствии должного ухода происходит резкая перестройка экосистемы лесополос [11, 12-14]. 


\section{Материалы и методы}

Цель исследований - инвентаризация защитных лесных насаждений на территории Волчковского сельсовета Белинского района с целью сохранения и восстановления агролесомелиоративного фонда.

Объект исследований - земли сельскохозяйственного назначения, на которых расположены лесные защитные насаждения Волчковского сельсовета Белинского района.

По категориям земельный фонд Волчковского сельсовета Белинского района распределен следующим образом: 75,8 \% занимают земли сельскохозяйственного назначения; 4,3\% - земли населенных пунктов; 0,5 \% - земли промышленности, энергетики, транспорта и иного специального назначения; 19,4\% - земли лесного фонда.

Предмет исследований - изучение правового статуса, качественной и количественной оценки защитных лесных насаждений, выявленных в результате анализа и оценки пространственных данных с применением ГИС-технологий.

Методы исследований: фотограмметрический, системный анализ.

В научной работе при инвентаризации защитных лесных полос использовались следующие данные:

- материалы спутниковой съемки из интерактивного приложения SAS planet (пространственное разрешение около 0,5 м);

- материалы спутниковой съемки Landsat 8, диапазон OLI (пространственное разрешение 2,1 м);

- Веб-приложение «Публичная кадастровая карта».

\section{Результаты}

Одним из наиболее передовых, эфрфективных и надежных источников инфрормации о свойствах сельскохозяйственных земель и о состоянии посевов являются данные дистанционного зондирования Земли (Д33). Основными преимуществами системы дистанционного мониторинга является оперативность получения информации, объективность, единовременность и периодичность, единообразие, обзорность и комплексное решение широкого круга прикладных задач сельского хозяйства.

Для функционирования системы мониторинга используются данные дистанционного зондирования с различными характеристиками. В качестве основы для выполнения мониторинга сельскохозяйственного производства могут быть использованы космические снимки среднего (10-50 м), высокого (1-10 м) и сверхвысокого (менее 1 м) пространственного разрешения.
Трансформация растра осуществлялась по абсолютным координатам опорных точек, представленных в системе МСК-58. Создание векторной карты осуществлялось в ГИС Панорама.

Для получения большей полноты данных до начала проведено визуальное дешифрирование актуальных спутниковых снимков (2016-2018 годов съемки) с составлением векторного полигонального слоя текущего местоположения защитных лесных насаждений. Количество дешифрированных объектов составило 110 ед., общая площадь - 199,2 га.

Следующим шагом было определение категорий земель, на которых располагаются лесные полосы. Для этого в ГИС совмещены wms-сервисы web приложения «Публичная кадастровая карта Российской Федерации» с актуальным полигональным слоем полезащитных лесных насаждений. Далее была заполнена атрибутивная информация по категории земель по каждой полосе. В результате проведенных работ установлено, что полезащитные лесные полосы располагаются на землях с неучтенными категориями и фрормами собственности.

В рамках научной работы лесные полосы условно сгруппированы по следующим категориям: полезащитные, придорожные, прибалочные и приовражные. В категорию «полезащитные» включены все лесные полосы, рас положенные в непосредственной близости от сельскохозяйственных угодий (полей, садов, пастбищ и т. д.). В категорию «придорожные», соответственно, включены лесные полосы, расположенные вдоль автотрасс. Категория «при- овражные» включила в себя лесные полосы, расположенные вдоль балок, оврагов и других водных (рельефных) объектов местности.

Для определения текущего состояния лесных полос был рассчитан вегетационный индекс NDVI, показывающий количество фотосинтетически активной биомассы растительного покрова. NDVI - это один из самых распространенных вегетационных индексов для решения задач, использующих количественные оценки растительного покрова.

Расчет NDVI базируется на двух наиболее стабильных (не зависящих от прочих факторов) участках спектральной кривой отражения сосудистых растений. В красной области спектра (0,6-0,7 мкм) лежит максимум поглощения солнечной радиации хлорофиллом высших сосудистых растений, а в инфрракрасной области (0,7-1,0 мкм) находится область максимального 
отражения клеточных структур листа, т. е. высокая фотосинтетическая активность (связанная, как правило, с густой растительностью) ведет к меньшему отражению в красной области спектра и к большему - в инфракрасной.

В расчете NDVI использованы мультиспектральные (комбинация каналов Red + NIR) спутниковые снимки с космического аппарата Landsat 8.

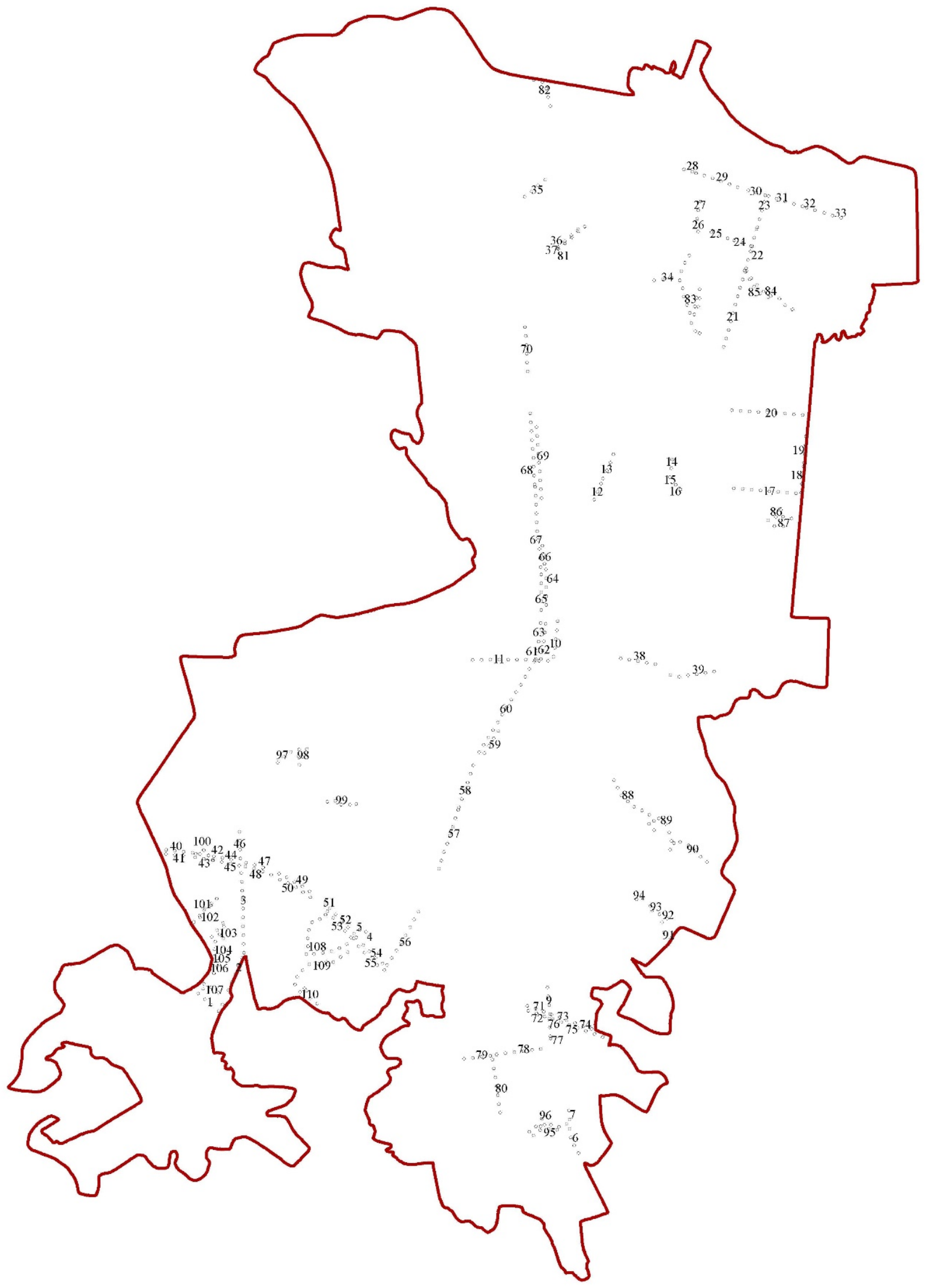

Векторная карта расположения лесных защитных насаждений 
Для более качественного расчета выбраны спутниковые снимки на даты близких фенологических фраз растений (июнь 2018 г.), а также ряд эталонных объектов (участок здорового леса, участок сельскохозяйственных земель, кустарниковая растительность и т. д.) для контроля и коррекции измерений вегетационного индекса.

Если среднее значение NDVI по лесной полосе превышает 0,7 , это соответствует полосе, не требующей мероприятий по восстановлению (обновлению). Если значения NDVI находятся в диапазоне от 0,5 до 0,7 , то для данной полосы необходимы мероприятия по восстановлению (обновлению) посадок. У полностью утраченных лесных полос значение NDVI ниже 0,5.

По результатам выполнения данного этапа составлена карта расположения лесных полос по состоянию (рисунок), а также проведен анализ, в результате которого установлено, что:

- состояние, не требующее проведения мероприятий по восстановлению (обновлению), имеют 77 лесных полос, общей площадью 127,1 га;

- состояние, требующее мероприятий по восстановлению (обновлению), актуально для 31 лесной полосы площадью 70,4 га;

- полностью утраченная одна лесная полоса площадью 1,7 га.

\section{Заключение}

С целью сохранности защитных лесных насаждений на землях сельскохозяйственного назначения разработана дорожная карта мероприятий, которая включает:

1. Создание рабочих групп с привлечением специалистов отдела по управлению земельными ресурсами Департамента Государственного имущества Пензенской области, Министерства сельского хозяйства, Министерства лесного, охотничьего хозяйства и природопользования, администрации муниципальных районов и сельсоветов.

2. Формирование отделом по управлению земельными ресурсами Департамента Государственного имущества Пензенской области реестра защитных лесных полос.

3. Определение правового статуса земельных участков, занятых защитными лесными полосами (собственность, землевладение, землепользование, аренда) специалистами отдела;

4. Проведение работ по оформлению прав на земельные участки, занятые защитными лесными полосами.

5. Проведение Министерством лесного, охотничьего хозяйства и природопользования работ по посадке и уходу за защитными лесными полосами в рамках государственных контрактов.

\section{Лuтература}

1. О сохранении и воспроизводстве защитных лесных насаждений на землях сельскохозяйственного назначения: Закон Краснодарского края от 5 апреля 2010 г. N 1945-КЗ (с изменениями и дополнениями) [Электронный ресурc]. URL: http://www.kaicc.ru/node/1018.

2. Лошаков, А. В. Инвентаризация защитных лесных насаждений террас реки Кубани / А. В. Лошаков, С. И. Лопатин, С. С. Ткаченко // В мире научных открытий. - 2011. - № 9-4 (21). C. $1247-1254$.

3. Сучков, Д. К. Роль и экономическая эфффективность защитных лесных насаждений в восстановлении и преобразовании ландшафртов / Д. К. Сучков // Научно-агрономический журнал. 2018. - № 1 (102). - С. 20-23.

4. Михайлова, Н. В. Пути предотвращения распада лесных экосистем, выполняющих защитные функции / Н. В. Михайлова // Стратегия устойчивого развития регионов России. - 2010. № 2. - C. 114-115.

5. Евдокимов, Е. В. Стратегия создания зеленых полос в регионах России / Е. В. Евдокимов // Инновационная наука. - 2017. - Т. 2. - № 3. - С. 33-35.

6. Лёвина, И. В. Особенности воспроизводства и эффрективность использования земельных ресурсов / И. В. Лёвина // Вестник сельского развития и социальной политики. - 2018. - № 3 (19). - C. $42-45$.

7. Савинова, А. И. Защитные лесные насаждения в восстановлении и преобразовании природно и антропогенно нарушенных ландшафтов / А. И. Савинова // Аллея науки. - 2016. - № 4. C. 104-107.

8. Мелиоративная роль лесной полосы в формировании урожайности озимой пшеницы в засушливой зоне Ставропольского края / Л. В. Трубачёва, О. В. Мухина, Н. С. Чухлебова, А. М. Никифорова, Д. А. Шевченко // Вестник АПК Ставрополья. - 2018. - № 2 (30). - С. 179-182.

9. Троц, Б. Б. Влияние полезащитных лесных полос на состояние и продуктивность агроландшафта / В. Б. Троц // Аграрная Россия. - 2017. - № 11. - С. 19-22.

10. Троц, В. Б. Агроэкологическое влияние полезащитных лесных полос / В. Б. Троц // Известия Оренбургского государственного аграрного университета. - 2016. - № 4 (60). - С. 189-192.

11. Демиденко, Г. А. Агроэкологическая роль полезащитных лесных полос в ландшафтах Красноярской лесостепи / Г. А. Демиденко // Вестник Красноярского государственного аграрного университета. - 2018. - № 3 (138). - С. 8-12. 
12. Effects of farmland shelterbelts in controlling wind and sand in sandy land of Yanchi / Q. Cui, J. Gao, M.-Y. He, Z.-G. Zhao, J.-R. Zhang // Journal of Ecology and Rural Environmentю - 2009. V. 25. - № 3. - P. 25-29.

13. A synoptic land change assessment of Ethiopia's Rainfed Agricultural Area for evidence-based agricultural ecosystem management / T. Kassawmar, G. Zeleke, A. Bantider, G. D. Gessesse, L. Abraha // Heliyon. - 2018. - V. 4. - № 11.

14. Tolunay, A. Definition and classification of traditional agroforestry practices in the West Mediterranean Region of Turkey / A. Tolunay, M. Korkmaz, H. Alkan // International Journal of Agricultural Research. - 2007. - V. 2. - № 1. - P. 22-32.

UDC $630 * 232$

DOI: 10.36461/NP.2019.52.3.011

\section{COMPARTMENT DESCRIPTION OF SHELTERBELT FORESTS ON AGRICULTURAL LANDS}

S. V. Bogomazov, Candidate of Agricultural sciences, assistant-professor;

O. S. Balakireva, student; E. V. Efremova, Candidate of Agricultural sciences, assistant-professor;

O. A. Tkachuk, Candidate of Agricultural sciences, assistant-professor;

A. V. Lyandenburskaya, senior lecturer; A. A. Levin, assistant

Federal state budgetary educational institution of higher education «Penza State Agrarian University», Russia, t. (8412) 628546, e-mail:s_bog@mail.ru

The article provides an analysis of economic use of shelterbelt forests on agricultural lands. The aim of the research was a compartment description of shelterbelt forests on the territory of the Volchkovsky village council of the Belinsky district in order to preserve and restore the stock of reclamative afforestating land. In the laboratory conditions, an up-to-date cartographic material was created on the basis of high-resolution and ultra-high-resolution satellite images, visual interpretation was made with the preparation of a vector polygonal layer of the current location of the shelterbelt forests, the number of decrypted objects, their legal status and total area (199.2 ha) were determined. The calculation of the NDVI index showed that the state, not requiring restoration (updating) measures, had 77 forest strips with a total area of 127.1 hectares; a condition requiring restoration (renewal) measures was relevant for 31 forest strips with an area of 70.4 ha; one forest strip with an area of 1.7 hectares was completely lost. A roadmap for the conservation of the stock of reclamative afforestating land was developed.

Key words: inventory, shelterbelt forests, agricultural land, geographical information systems.

References:

1. On the conservation and reproduction of shelterbelt forests on agricultural lands: Law of the Krasnodar Territory of April 5, 2010 N 1945-KZ (amended and supplemented) [Electronic resource]. URL: http://www. kaicc. ru/node/1018.

2. Loshakov, A. V. Inventory of shelterbelt forests of terraces of the Kuban river / A. V. Loshakov, S. I. Lopatin, S. S. Tkachenko // Siberian Journal of Life Sciences and Agriculture. - 2011. - No. 9-4 (21). - p. 1247-1254.

3. Suchkov, D. K. The role and economic efficiency of shelterbelt forests in the restoration and transformation of landscapes / D. K. Suchkov // Nauchno-agronomicheskiy zhurnal. - 2018. - No. 1 (102). - p. 20-23.

4. Mikhailova, N. V. Ways to prevent the decay of forest ecosystems that perform protective functions / N. V. Mikhailova // Strategiya ustoichivogo razvitiya regionov Rossii. - 2010. - No. 2. - p. 114-115.

5. Evdokimov, E. V. The strategy of creating green stripes in the regions of Russia I E. V. Evdokimov // Innovatsionnaya Nauka. - 2017. - V. 2. - No. 3. - p. 33-35.

6. Levina, I. V. Features of reproduction and land use efficiency / I. V. Lyovina // Bulletin of rural development and social policy. - 2018.-- No. 3 (19). - p. 42-45.

7. Savinova, A. I. Shelterbelt forests in the restoration and transformation of natural and man-made disturbed landscapes / A. I. Savinova // Alley-Science. - 2016. - No. 4. - p. 104-107.

8. The reclamation role of the forest strip in the formation of winter wheat productivity in the arid zone of the Stavropol Territory /L. V. Trubacheva, O. V. Mukhina, N. S. Chukhlebova, A. M. Nikiforova, D. A. Shevchenko // Bulletin of the agricultural industry of Stavropol. - 2018.-- No. 2 (30). - p. 179-182.

9. Trots, V. B. The influence of forest shelter belts on the state and productivity of the agrolandscape / V. B. Trots // Agrarian Russia. - 2017. - No. 11. - p. 19-22.

10. Trots, V. B. Agroecological influence of field-protecting forest strips / V. B. Trots // Bulletin of the Orenburg State Agrarian University. - 2016. - No. 4 (60). - p. 189-192. 
11. Demidenko, G. A. Agroecological role of shelterbelt forests in landscapes of the Krasnoyarsk forest-steppe / G. A. Demidenko // Bulletin of the Krasnoyarsk State Agrarian University. - 2018.-- No. 3 (138). - p. 8-12.

12. Effects of farmland shelterbelts in controlling wind and sand in sandy land of Yanchi / Q. Cui, J. Gao, M.-Y. He, Z.-G. Zhao, J.-R. Zhang // Journal of Ecology and Rural Environment. - 2009. - V. 25. - № 3. - P. 25-29.

13. A synoptic land change assessment of Ethiopia's Rainfed Agricultural Area for evidence-based agricultural ecosystem management / T. Kassawmar, G. Zeleke, A. Bantider, G. D. Gessesse, L. Abraha // Heliyon. - 2018. - V. 4. - № 11.

14. Tolunay, A. Definition and classification of traditional agroforestry practices in the West Mediterranean Region of Turkey / A. Tolunay, M. Korkmaz, H. Alkan // International Journal of Agricultural Research. - 2007. - V. 2. - № 1. - P. 22-32. 